\title{
A neuropathological study of familial dysautonomia (Riley-Day syndrome) in siblings
}

\author{
W. JANN BROWN, J. A. BEAUCHEMIN, AND LEONARD M. LINDE \\ From the Departments of Pathology (Division of Neuropathology) and Paediatrics, \\ University of California, School of Medicine, Los Angeles, California
}

Riley, Day, Greeley, and Langford (1949) described the clinical features of a disturbance of the autonomic nervous system manifested by skin blotching, fluctuations in blood pressure, erratic temperature control, disturbances of the swallowing reflex, hyperhidrosis, and diminished or absent lacrimation. Additional signs of neurological involvement included incoordination, relative insensitivity to pain, diminished deep tendon reflexes, emotional lability, and disturbances of the gastrointestinal tract with episodes of severe vomiting.

While this widespread involvement of the nervous system was evident clinically, attempts to elucidate the histopathology and pharmacopathology have met with only partial success. The aetiology and pathogenesis of this condition remains obscure.

Aring and Engel (1945a, 1945b) reported clinical and pathological studies in a patient who had 'hypothalamic attacks' and at necropsy an old cystic lesion was found in the thalamus. These authors postulated repeated paroxysms of hypothalamic overactivity because of disruption of corticohypothalamic association tracts described by Magoun (1939) which coursed through a cystic degenerative lesion of the dorsomedial and lateral nuclei of the right thalamus. The clinical descriptions of the 'hypothalamic attacks' are those of dysautonomia.

In a more recent necropsy study of a typical case of dysautonomia, Cohen and Solomon (1955) found the pons and medulla grossly smaller than normal due to alterations in the reticular formation. No aetiological clues could be found. These authors believed that the pathological changes had occurred in tracts similar to those described by Magoun (1939) in cats. These tracts arise in the lateral hypothalamus and descend to preganglionic sympathetic neurons of the spinal cord. In the medulla, these tracts are situated largely in the lateral reticular formation.

Recently Riley (1957) presented a comprehensive review of this condition. He reviewed three new cases. In one case there were multiple brain abscesses, presumably secondary to an aspiration type pneu- monia. In the other cases abnormalities of the central nervous system were sought using the Cohen and Solomon (1955) criteria. but none were found. No note was made of any examination of the peripheral nervous system.

The two cases in siblings reported here are significant in that the abnormalities described by Cohen and Solomon (1955), and to some extent by Aring and Engel (1945a), were present. In addition, changes in the dorsal longitudinal bundle in the brain-stem, spino-thalamic tracts of the cord and medulla, ascending dorsal columns, and spinocerebellar tracts were found. Also included in the report is a detailed study of significant changes in autonomic ganglia and peripheral nerves.

\section{MATERIALS AND METHODS}

The brains of both cases and the spinal cord of case 1 were fixed in $10 \%$ neutral formalin. Other tissues were fixed in both Zenker's solution and $10 \%$ neutral formalin. An extensive dissection was carried out on case 1 and eyes, muscles, lacrimal glands, tongue, vagus, peroneal, femoral nerves, brachial plexus, and autonomic nerve chains were all sampled and placed in both fixatives. Autonomic ganglia from the coeliac plexus and the thoracic and pelvic regions were taken. The brain in case 2 was coronally sectioned and embedded in both celloidin and paraffin. The brain and spinal cord in case 1 were similarly cut and embedded only in paraffin. The brains and cord were sectioned subserially and stained using multiple histopathological techniques (Weil, haematoxylin and eosin, Holzer, Nile blue sulphate, Luxol fast blue, Bielschowsky, and Bodian preparations). Tests for melanin, iron, lipofuscin and periodic acidSchiff (P.A.S.)-positive materials were done on tissue sections of autonomic ganglia using methods described by Pearse (1960).

\section{CASE REPORTS}

CASE 1 The clinical details of this case have been extensively treated in another context by Linde (1956). The following is only a brief clinical abstract:

J.S., a 2-year-old Jewish girl, was noted on the second day of life to have hypotonia, hypertension, poor colour, 


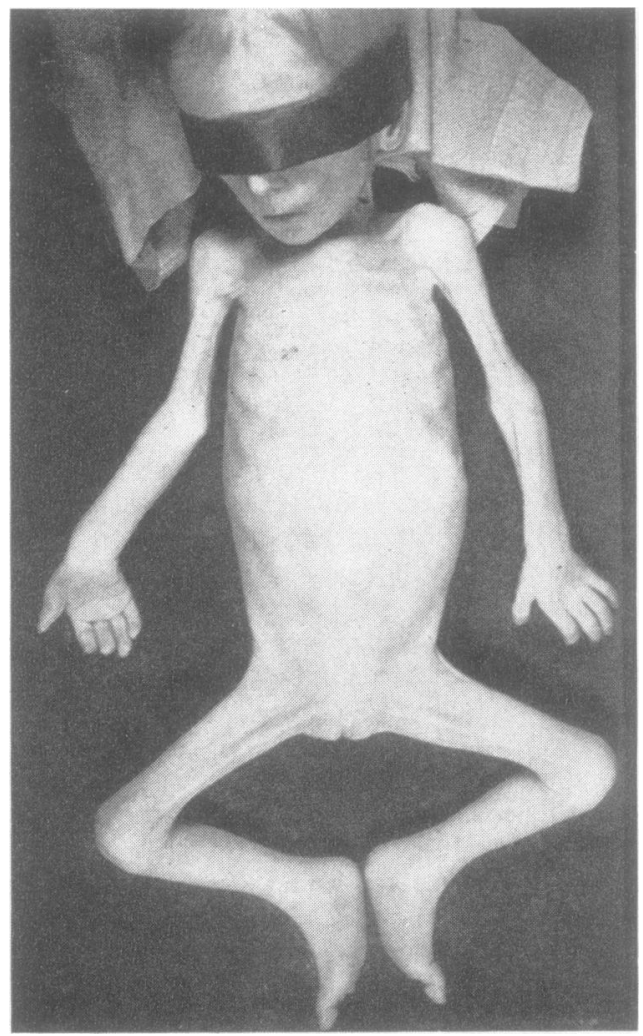

FIG. 1. Case l at $2 \frac{1}{2}$ years of age. Note extreme loss of tissue.

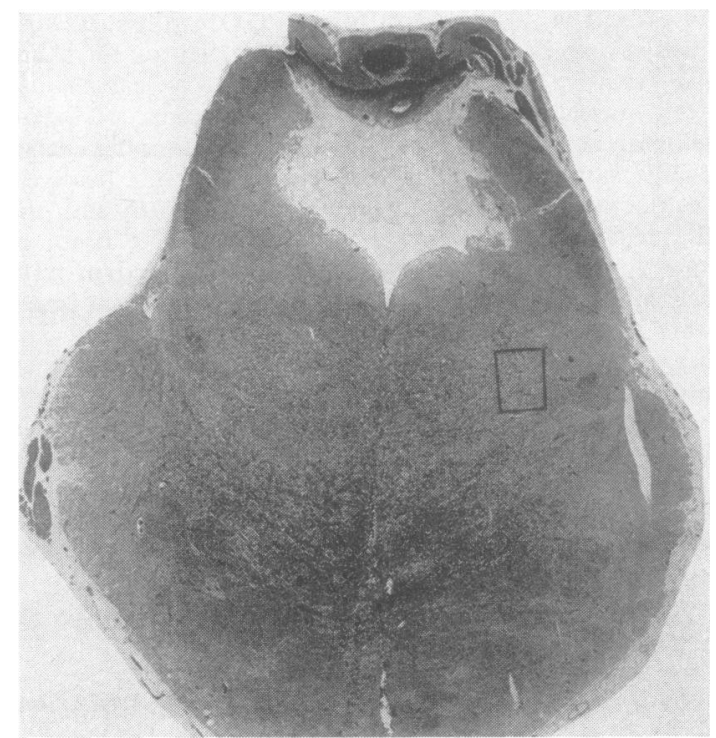

FIG. 2. Pons in case 1. Note enlarged fourth ventricle, lack of abnormality of cortico-spinal tracts, and slight spongy appearance of reticular formation in insert. Weil $\times 8$. poor feeding, and defective swallowing. 'Dysautonomia' was diagnosed and she was placed in a nursing home by the parents. During her stay in hospital she consistentlyœ failed to gain weight and died after a 'progressive downhill course'. The baby never produced tears and was $\square$ insensitive to pain. She had recurrent aspiration pneu monia. The terminal episode was related to aspiration. The mother had cancer of the thyroid and had been⿳亠丷厂 treated by local irradiation some time before conception $\overrightarrow{\vec{z}}$

Necropsy revealed an emaciated 2-year-old white female (Fig. 1) who measured $58 \mathrm{~cm}$. from crown to heel; head circumference was $38 \mathrm{~cm}$. The total body weightwas $2,600 \mathrm{~g}$. Both corneas were opaque. There were $\frac{\bar{\sigma}}{\sigma}$ multiple deformities and fibrotic scars in the tongue. The $\overline{\bar{s}}$ upper teeth were intact, but only one tooth was present $\overbrace{\widehat{\sigma}}$ in the lower jaw. The skeletal muscle was thin and@ atrophic. There was bronchopneumonia and focal atelectasis. The oesophagus and colon were moderately $\rightarrow$ dilated. The adrenals weighed $2.0 \mathrm{~g}$. together. Micro-. scopically extensive fibrous scarring of the tongue and $\overrightarrow{\vec{c}}$ serous atrophy of body fat were noted. In the focal ${ }^{\omega}$ atelectatic regions the alveoli contained foamy fat filled macrophages and occasional giant cells. The zona? reticularis of the small adrenals contained copious amounts of golden-brown pigment. The lacrimal gland. $N$ epithelium was slightly atrophic and cells contained a few! vacuoles, but neural elements of the gland were normal. $\vec{\omega}$ Numerous small capillaries in the iris beneath the pig- $\overrightarrow{-}$ ment layer, as well as focal parakeratosis of corneal epithelium, were noted in sections of the eyes.

Neuropathological findings The neuropathologieal findings included, on gross examination, several smalle. gyri in the frontal and posterior parietal lobes and largement of the fourth ventricle (Fig. 2). The contoursfos the spinal cord appeared normal. On microscopic ${ }^{+}$ examination the veins and capillaries of the leptomeninx, cortical and subcortical white matter were engorged. Sharply defined enlarged perivascular spaces were noted. Cortical lamination was distinct, but manyฏ neurones of the third, fifth, and sixth layers of the frontali lobes were poorly stained, had vacuoles, and little Nissl substance. Subcortical myelination was not complete $\overrightarrow{\bar{O}}$ but its extent was consistent with the child's age. Mye- 3 linated tracts and fibres in the basal ganglia appeared normal, but there were a few scattered petechiae andọ occasional vacuolated neurones. No pathological altera $=$ tions of the tracts and nuclei of the thalamus were found. Infantile multilayered ependymal cells were still present? along the edges of the lateral ventricles. The cell population and general architecture in both anterior and. posterior segments of the hypothalamus were normal. The pars distalis of the pituitary gland was congested. 3 The substantia nigra was not pigmented. The myelino sheaths of the lower and mid-pontine reticular formation were sparse (Fig. 3a). In longitudinal sections 'digestion chambers' could be seen, along with variously shaped swellings along the myelin sheaths. Only an occasionalN small sheath could be seen in some regions that normally contained a large amount of myelin. Phagocytic activity was not seen. There was, however, a slight increase in the number of astrocytes present. The pontine nuclei ando brachium conjunctivum appeared normal. The spino- 


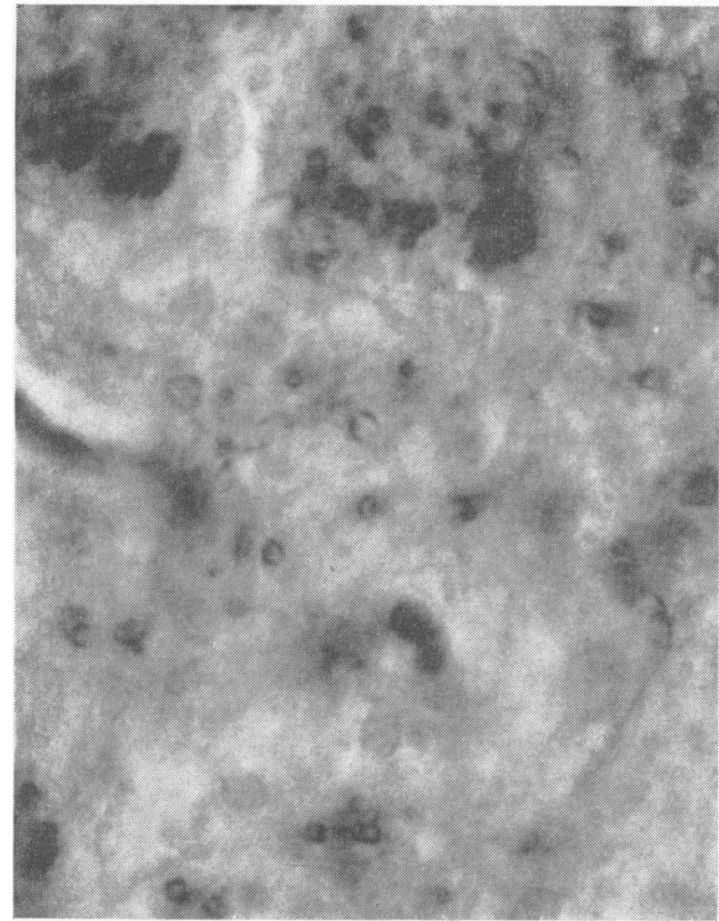

FIG. 3a

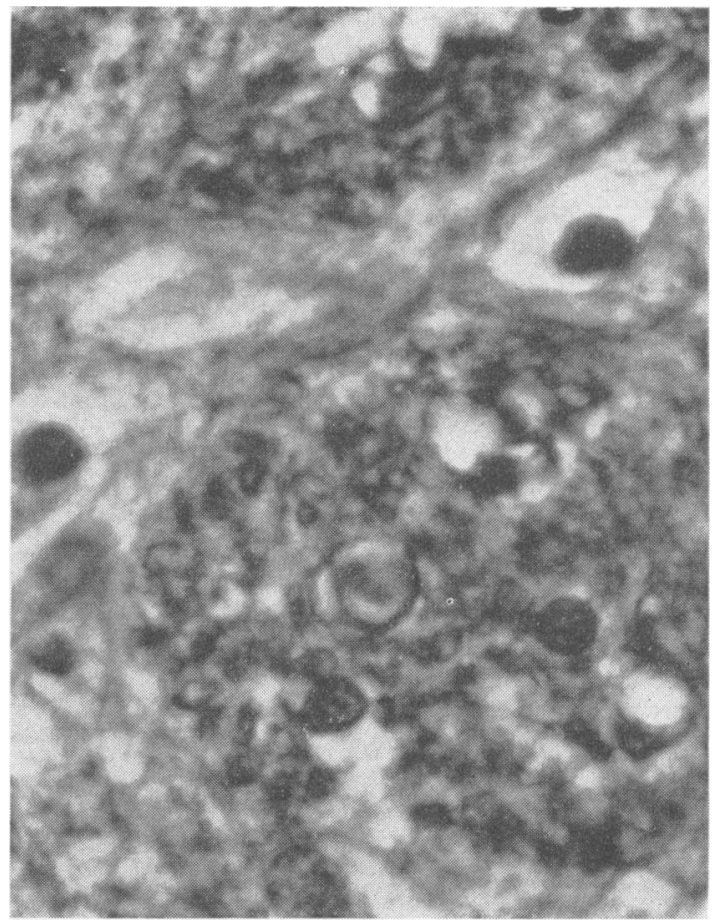

FIG. $3 \mathrm{~b}$

FIG. 3a. Note absent and distorted myelin sheaths in reticular formation of pons taken from insert of Figure 2. There are occasional astrocytes present, but no oligodendroglia. Note lack of reactive cell response. Compare density of the sheaths with similar region of reticular formation in normal pons. Weil $\times 460$.

FIG. 3b. Reticular formation from normal pons. Note compact dense fascicles of myelin sheaths with scattered oligondendroglia. Weil $\times 460$.

FIG. 4. Note swollen, ballooned, and degenerated myelin sheaths in cross section of ascending posterior columns of cervical spinal cord in case 1. The fasciculus gracilis is shown but both fascicles were involved. Weil $\times 300$.

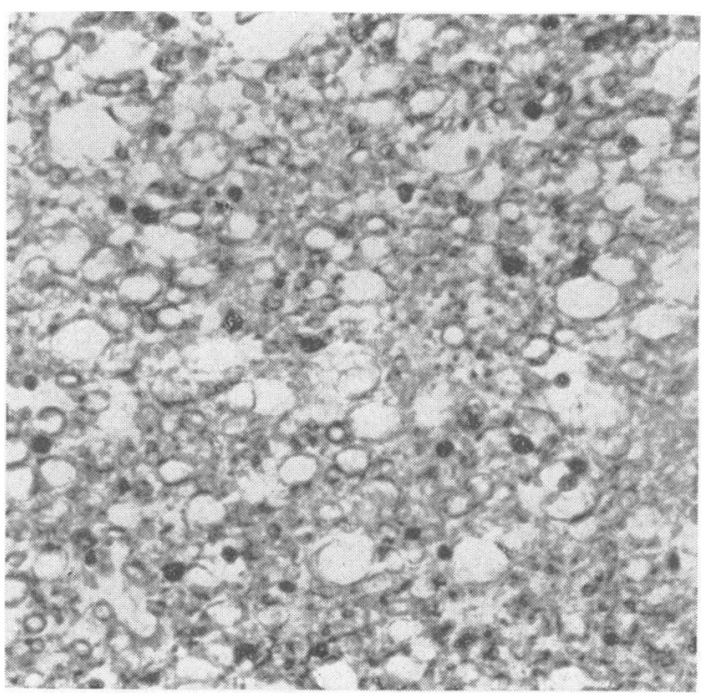


thalamic fasciculus was partially demyelinated and no reactive cells were present in and around the tract. The myelin of the dorsolongitudinal fasciculus was distorted and more sparse than that of normal tracts. There were scattered irregular sheaths in the mesencephalic tract of the fifth nerve in the mesencephalon and pons. In the cerebellum there were a few scattered foci of primitive neuroblasts in the molecular layer and occasional lost Purkinje cells, but there were no changes in the supporting glia or granular cell layer. The cranial nerves and nuclei of the medulla appeared normal. A few fibres along the lateral edges of the medial lemniscus were distorted. The change in the nearby reticular formation was pronounced. Sheaths were lost, some distorted, others were merely ghosts, but neither phagocytic response nor free fat was found. The neuron population of the reticular formation was less than normal, but this change was not striking. There was no evident demyelination of the inferior olives or restiform bodies. Spongy forms and irregular enlarged 'digestion chambers' were noted in the myelin sheaths at all levels of the fasciculus gracilus and cuneatus, but the change was most pronounced in the former (Fig. 4). The spinothalamic tracts, both lateral and ventral, and to a lesser extent, the spinocerebellar tracts, showed myelin and axis cylinder alterations similar to those of the posterior columns. The lateral and ventral corticospinal tracts appeared normal for this age, as did the ventral roots. $\mathcal{D}$ Numerous segments of the peroneal and femoraf nerves, as well as elements of the brachial plexus, werew examined, and only an occasional sheath was demyelinated. Posterior roots, on the other hand, did have irregular loss of myelin sheaths, as well as scattereden ballooned and spongy alterations in sheaths (Fig. 5). Sympathetic fibres of the thoracic and cervical chains, and vagus nerves in general had normal axon cylinders $\overrightarrow{2}$ but there were scattered irregular enlargements, and lost: fibres were replaced by proliferated fibrocytes. Round vacuoles of various sizes were noted in the cytoplasm of ganglion cells of the sympathetic chains. Fat stains, P.A.S. preparations, iron and protein stains, all failed to characterize the vacuoles. Some of the ganglion cells of the coeliac plexus and pelvic ganglia (Fig. 6) contained dense masses of material in the cytoplasm which re-n sembled lipochrome. Bodian and Masson Fontana pre-parations showed the argyrophilic nature of this material, The Gomori silver methenamine test failed to show any reducing properties in the cytoplasmic granules. In general, the argyrophilic material was finely divided and sprinkled near the nucle as of the cell. Though myenteric plexuses were prominent throughout the oesophagus stomach, pyloric junction, small bowel, and vermiform appendix, the ganglion cells had a bright eosinophilicu

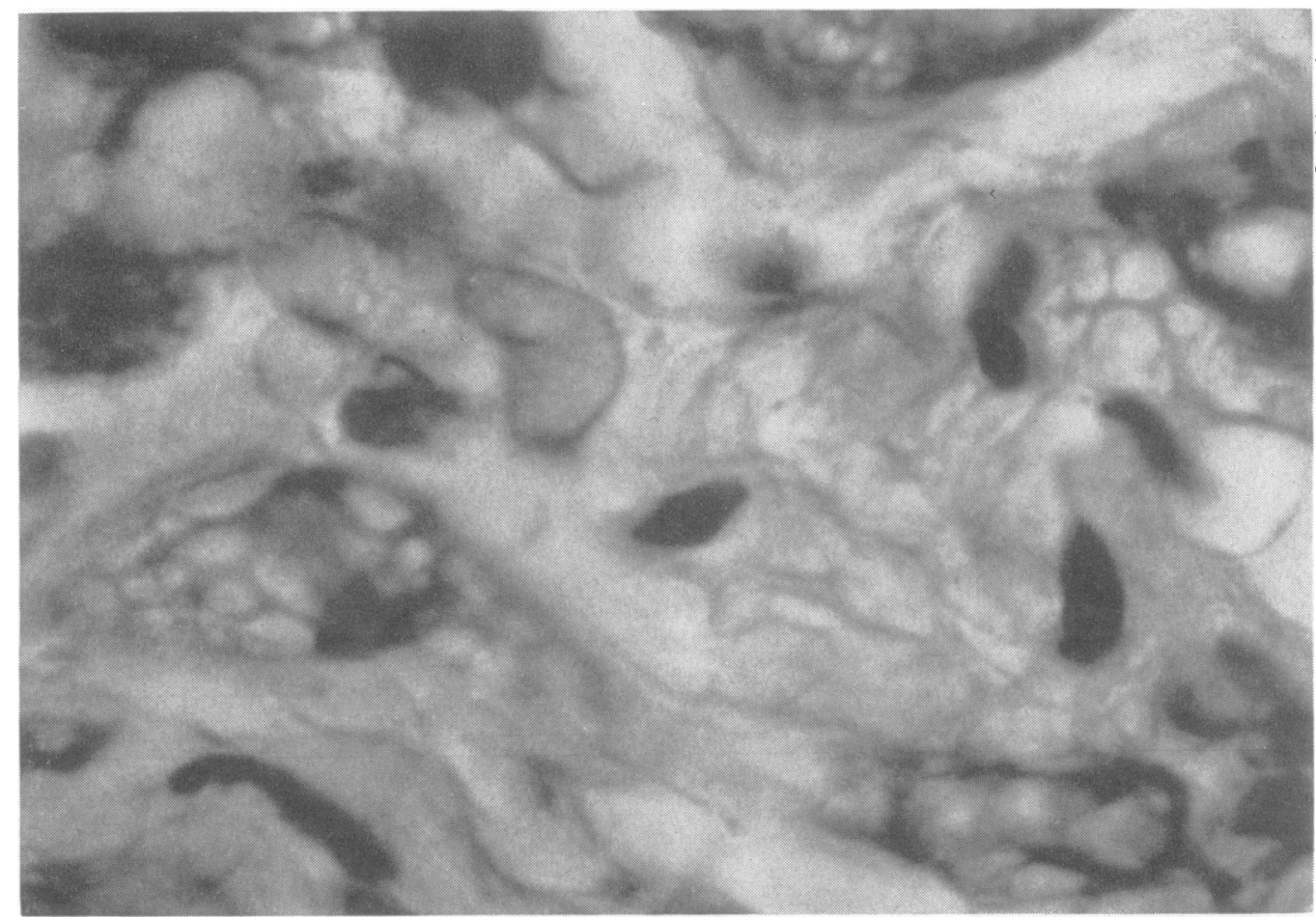

FIG. 5. Ganglion cells in coeliac plexus of case 1. Note degenerated, irregular cells with masses of silver deposited in cytoplasm and obscuring the nucleus. Also note discrete granules in cytoplasm of other cells. Bodian preparation. $\times 200$. 


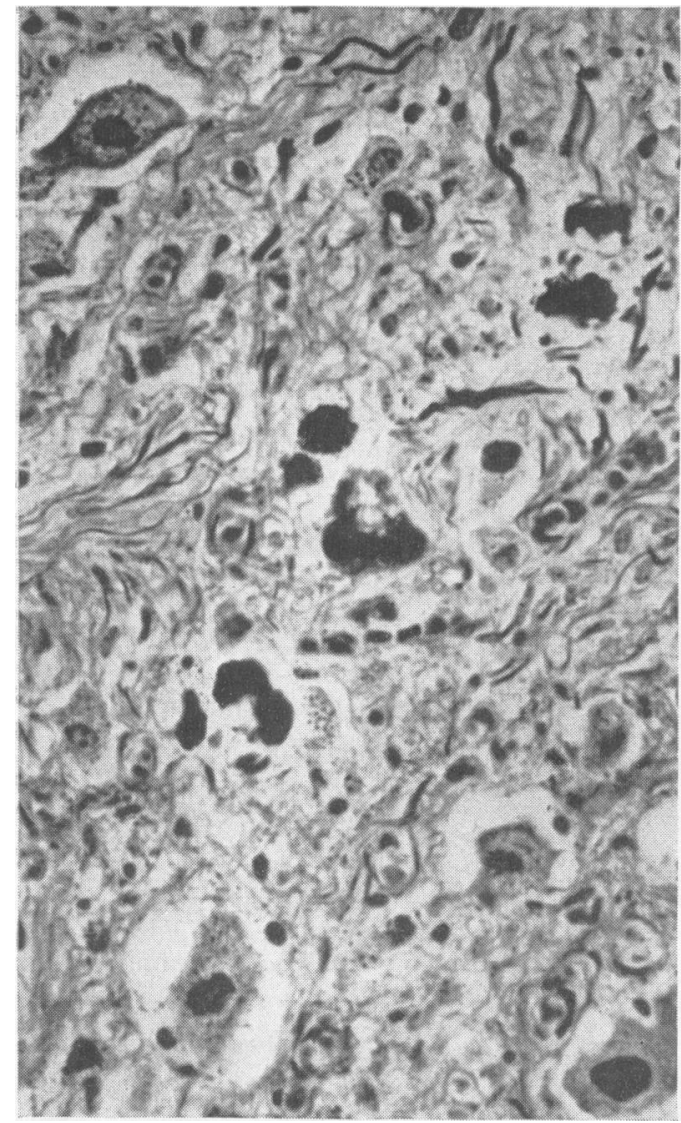

FIG. 6. Swollen, bulging myelin sheaths from posterior root of case 1. Note large bubbles in 'digestion chambers' of some sheaths contributing to transparency of the sheath. Weil $\times 2,070$.

cytoplasm but lacked the argyrophilic masses similar to those of the coeliac plexus ganglia.

CASE 2 S.S., an 8-year-old boy, died after his fifteenth admission to hospital. The details of his extensive and complicated clinical history have been reported by Linde (1956). In summary, the numerous admissions were for various combinations of autonomic and neurological dysfunction which included aspiration pneumonia, atelectasis, cyanosis, apnoea, vomiting, fever, abdominal distention, cough, flaccidity, arreflexia, incoordination, deficient lacrimation, indifference to pain in relation to traumatic ulceration of the tongue, anorexia, convulsions, dehydration and acidosis, choking spells, disorientation, hysteria, and, finally, shock and coma in relation to dehydration and vomiting.

Necropsy revealed an undersized boy with markedly diminished body fat and poorly formed pale musculature. The trachea and major bronchi bilaterally contained a considerable amount of mucopurulent bloody fluid. The lung parenchyma contained foci of consolidation and irregular patches of atelectasis. The left ventricle of the heart was hypertrophied. The liver and kidneys were atrophic. The adrenals weighed $7 \mathrm{~g}$. (normal, 12.5 g.).

Microscopic examination revealed bronchiolitis, focal fibrosis with calcinosis, and some giant cells in the pulmonary alveoli. The mucosa of the lower oesophagus was extensively ulcerated and overlay a thickened, fibrotic lamina propria.

Neuropathological findings The neuropathological findings included a gross brain weight of $1,039 \mathrm{~g}$. (normal, $1,273 \mathrm{~g}$.) which on section revealed an enlarged fourth ventricle and atrophy of the brain-stem (Fig. 7). The spinal cord, peripheral nerves, and sympathetic ganglia were not examined. The cerebrum was similar to that of case 1 except that the myelination was more advanced. The nuclei of the hypothalamus were normal. There were neither fibre changes nor neurone losses in the thalamus. The limbic system, mesencephalon, and choroid plexuses were severely congested and oedematous. There was some pigmentation of the substantia nigra.

The myelin sheaths of the reticular formation at the ponto-mesencephalic level of the brain-stem were swollen in a fusiform fashion with scattered focal balloons (Fig. 8). The lateral portions of the reticular formation at this level and in the pons and medulla had a greatly decreased incidence of myelin sheaths, although outlines of fascicles of sheaths could te seen. The sheaths of the grey portions of the reticular formation were also altered and diminished in number. The changes appeared both old and progressive. The recently altered fibres did not excite any phagocytic reaction, nor was any free fat found, but there were more astroglial nuclei in the reticular formation than in comparable control sections. At the mid-pontine level, the dorsal longitudinal tract of Schütz contained scattered enlarged degenerated myelin tubes amidst its sparsely myelinated fibres (Fig. 9).

There were similar changes in the contour of myelin sheaths of the mesencephalic tract of the fifth nerve. Structures of the medulla, exclusive of the reticular formation and including the medial lemniscus, medial longitudinal fasciculus, olives, seventh, eighth, ninth, tenth, eleventh, and twelfth cranial nerves and nuclei, all appeared without abnormality.

The medullary spino-thalamic tracts had lost many myelin sheaths and, in addition, contained sheaths in various stages of degeneration (Fig. 10). The restiform bodies were smaller than normal, but there were only a few sheaths that were changed. There were, however, neurones lost from both the dentate nucleus and the granular layer of the cerebellum. The granular cell loss was irregularly distributed, chronic and, again, had excited no reactive cell infiltration. The cortico-spinal tracts appeared normal at all levels. The myenteric plexuses of Auerbach and Meissner were normally distributed but both types contained cytoplasmic vacuoles in ganglion cells. Histochemical tests on these vacuoles, similar to those used in case 1 , showed no reaction.

\section{DISCUSSION}

The two cases presented here were siblings of Jewish extraction. The Jewish and sibling relationship has been observed in dysautonomia by Hutchison and 


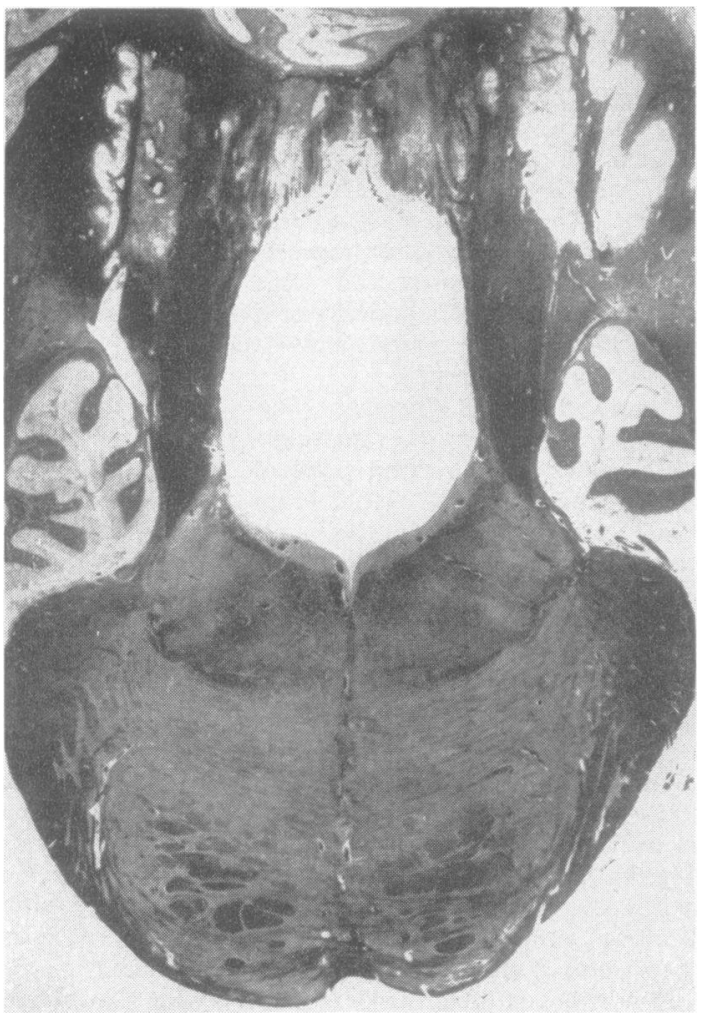

FIG. 7

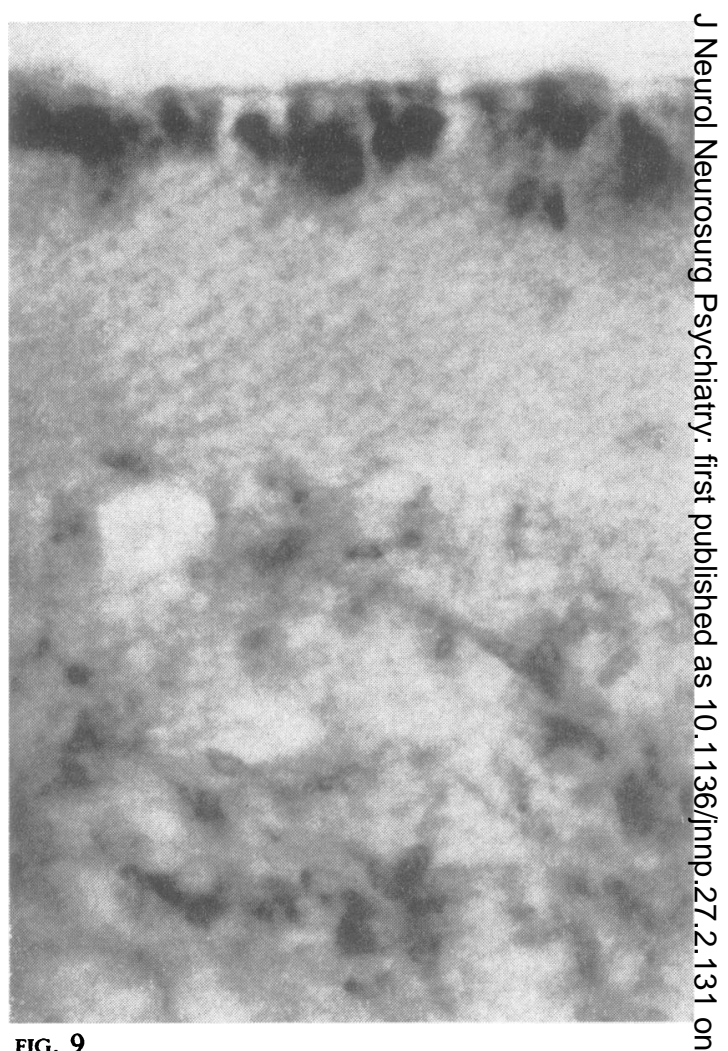

FIG. 7. Note enlarged fourth ventricle of pons with flattened tegmentum from case 2. Celloidin, Luxol blue. $\times 8 . \quad \underset{<}{\vec{x}}$ FIG. 9. Distorted sheaths of dorsal longitudinal fasciculus of (Schütz) with focal loss of myelin in case 2. Ependymal lin 8 of the fourth ventricle is normal. Celloidin, Weil $\times 2,070$.

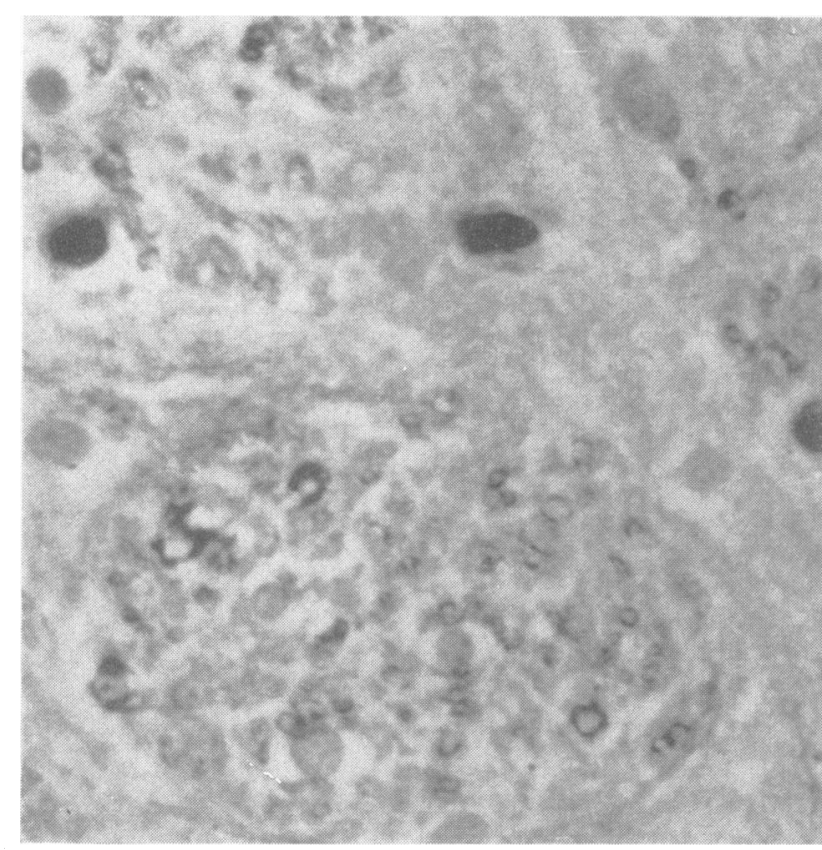

FIG. 8
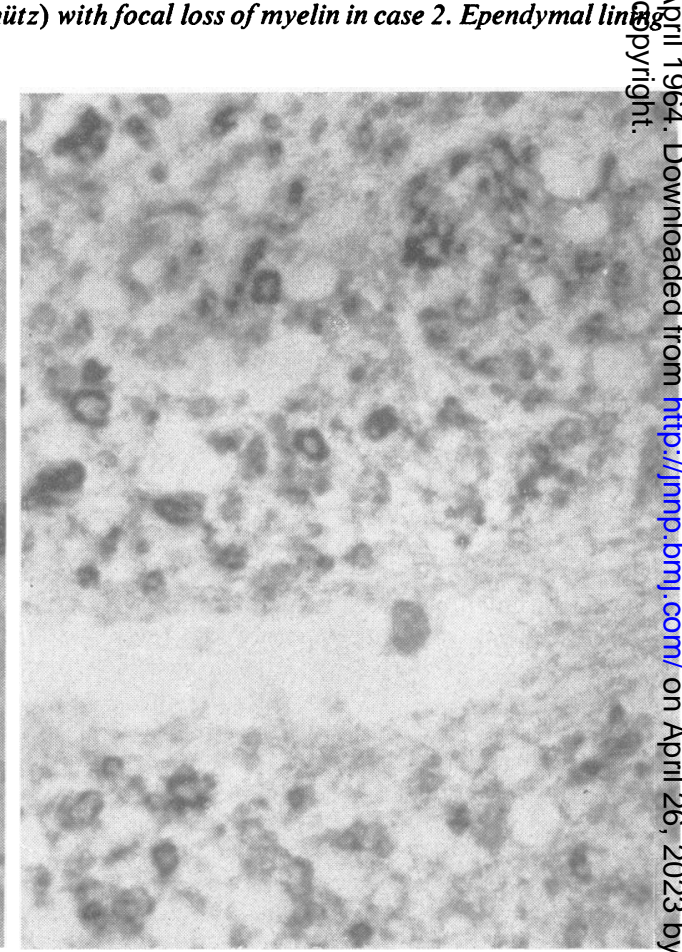

FIG. 10

FIG. 8. Absent and degenerating bundles of myelin sheaths of lateral reticular formation of medulla. Interfascicular fibres $\mathbb{D}$ are lost, and the oligondendroglia are decreased in case 2. Weil $\times 645$.

FIG. 10. Transverse section of the right spinothalamic tract showing reduction in myelin sheaths at midolivary level of 0 the medulla in case 2 . Weil $\times 645$. 
TABLE

\begin{tabular}{|c|c|c|c|c|c|}
\hline \multirow{3}{*}{$\begin{array}{l}\text { Case } \\
\text { Aring and Engel } \\
(1945 a, b)\end{array}$} & \multirow{2}{*}{$\begin{array}{l}\text { AL FEATU } \\
\text { Age and } \\
\text { Sex }\end{array}$} & OF PRESENT CASES & \multicolumn{3}{|c|}{ S COMPARED WITH PREVIOUSLY REPORTED NECROPSIED CASES } \\
\hline & & $\begin{array}{l}\text { Peripheral } \\
\text { Autonomic Nervous } \\
\text { System }\end{array}$ & $\begin{array}{l}\text { Pertinent Systemic } \\
\text { Findings }\end{array}$ & $\begin{array}{l}\text { Distribution of Lesions in Central } \\
\text { Nervous System }\end{array}$ & Cause of Death \\
\hline & $\begin{array}{l}18 \mathrm{yr} . \\
\mathrm{M}\end{array}$ & Not stated & $\begin{array}{l}\text { Severe physical } \\
\text { retardation }\end{array}$ & $\begin{array}{l}\text { Cystic malacia dorsomedial thalamic } \\
\text { nucleus, internal medullary lamina, } \\
\text { lateral nucleus, thalamus; petechiae } \\
\text { dorsal motor nucleus, vagus, and dorso- } \\
\text { longitudinal fasciculus; lateral reticu- } \\
\text { lar formation pons and medulla } \\
\text { demyelination; reduction cervical } \\
\text { anterior horn cells and upper dorsal } \\
\text { segments spinal cord; loss of myelin } \\
\text { in posterior columns }\end{array}$ & $\begin{array}{l}\text { Acute necrosis liver; } \\
\text { glomerulonephritis, } \\
\text { chronic bronchial } \\
\text { asthma, acute } \\
\text { bronchopneumonia }\end{array}$ \\
\hline $\begin{array}{l}\text { Cohen and Solomon } \\
\text { (1955) }\end{array}$ & $\begin{array}{l}3 \frac{1}{2} \text { yr. } \\
\text { M }\end{array}$ & Not stated & $\begin{array}{l}\text { Pes cavus, } \\
\text { physical retarda- } \\
\text { tion }\end{array}$ & $\begin{array}{l}\text { Demyelination reticular formation, } \\
\text { medulla, and lower pons; loss neurones } \\
\text { of cranial nerve nuclei floor of fourth } \\
\text { ventricle; some atrophy restiform body }\end{array}$ & $\begin{array}{l}\text { Haematemesis and } \\
\text { febrile episode }\end{array}$ \\
\hline Riley (1957) & & $\begin{array}{l}\text { Not stated } \\
\text { Not stated } \\
\text { Not stated }\end{array}$ & & $\begin{array}{ll}\text { Case 1 } & \text { Multiple brain abscesses } \\
\text { Case } 2 & \text { No lesions noted } \\
\text { Case } 3 & \text { No lesions noted }\end{array}$ & $\begin{array}{l}\text { Aspiration pneu- } \\
\text { monia }\end{array}$ \\
\hline $\begin{array}{l}\text { Hutchison and } \\
\text { Hamilton (1962) }\end{array}$ & $\begin{array}{l}15 \mathrm{mth} \text {. } \\
\mathrm{F}\end{array}$ & Not stated & $\begin{array}{l}\text { Physical re- } \\
\text { tardation }\end{array}$ & $\begin{array}{l}\text { Case } 1 \text { No anatomical abnormalities } \\
\text { noted }\end{array}$ & Bronchopneumonia \\
\hline Present case 1 & $\begin{array}{l}2 \text { yr. } \\
\text { F }\end{array}$ & $\begin{array}{l}\text { Degenerative pig- } \\
\text { mentary changes } \\
\text { ganglion cells, } \\
\text { coeliac plexus, } \\
\text { thoracic and pelvic } \\
\text { sympathetic ganglia }\end{array}$ & $\begin{array}{l}\text { Cachexia, } \\
\text { physical retarda- } \\
\text { tion }\end{array}$ & $\begin{array}{l}\text { Reticular formation, bilateral demye- } \\
\text { lination medulla and pons, atrophy } \\
\text { brain-stem, enlargement fourth ventricle; } \\
\text { focal myelin loss dorso-longitudinal } \\
\text { fasciculus; loss of sheaths ascending } \\
\text { posterior columns, spinothalamic tracts, } \\
\text { posterior roots and spinocerebellar } \\
\text { tracts; fibrosis cornea }\end{array}$ & $\begin{array}{l}\text { Aspiration pneu- } \\
\text { monia }\end{array}$ \\
\hline Present case 2 & 8 yr. & $\begin{array}{l}\text { Vacuoles in my- } \\
\text { enteric plexuses } \\
\text { (complete dissection } \\
\text { not done) }\end{array}$ & $\begin{array}{l}\text { Physical retarda- } \\
\text { tion, ulceration } \\
\text { of tongue }\end{array}$ & $\begin{array}{l}\text { Bilateral loss of myelin from reticular } \\
\text { formation, medulla, and pons, dorsal } \\
\text { longitudinal tracts, and spino- } \\
\text { thalamic tracts of medulla }\end{array}$ & $\begin{array}{l}\text { Vomiting, dehydra- } \\
\text { tion, aspiration } \\
\text { pneumonia, ulcera- } \\
\text { tive oesophagitis, } \\
\text { shock }\end{array}$ \\
\hline
\end{tabular}

Hamilton (1962). The Table summarizes the known facts relative to necropsied cases thus far reported in addition to the present case reports. Clinically, death in the present siblings was due to vomiting with numerous episodes of aspiration bronchopneumonia. In view of the physical state of these patients, it is difficult to rule out some overlay of changes in the nervous system due to malnutrition. Some of the lesions in the central nervous system in the two cases are in many respects similar in distribution and nature to the case reported by Cohen and Solomon (1955) but there are new findings in these cases that warrant comment. Essentially focal old and slowly progressive demyelination and or failure of development of myelin in the reticular formation was noted in the lower pons and medulla in both cases. Neurones, too, appeared to be decreased in the grey reticular formation, but most striking was loss of myelinated fibres within the grey substance, as well as in the lateral portion of the formation. The brain-stem of both cases was markedly decreased in size with concomitant enlargement of the fourth ventricle. The loss of reticular formation and dorsolongitudinal fasciculus portions of the tegmentum were responsible for the increase in size of the fourth ventricle.

Histologically, the significant changes in the myelin sheaths of the reticular formation were not as obvious as those found in the case described by Cohen and Solomon (1955). For instance, although 'digestion chambers' and other distortions of the sheath were noted in the reticular formation, there was no great profusion of such sheaths; rather, a general decrease in the staining was noted in the involved regions where sheaths appeared to be absent. In addition, no phagocytosis of degenerated myelin by gitter cells was noted nor were any extracellular fragments of these structures found. Fat stains of tissue from the reticular formation did not reveal any free fat. Moreover, there was little gliosis in the brain-stem. These features motivated against an acute or rapidly progressive demyelination in the brain-stem.

In the case study of Cohen and Solomon (1955) the focal demyelination of the reticular formation had a moderate phagocytic reaction with fat- 
positive gitter cells present, which indicated some progressive activity. The present cases had no such reaction at the time of death. It is entirely possible that relapsing episodes occur in the pathogenesis or that some of the changes represent failure of myelin development of small fascicles of sheaths from birth rather than degeneration. In both instances, at any one period, phagocytosis might be absent.

Cohen and Solomon (1955) did not mention changes in the dorso-longitudinal tract of Schütz, but in the present two cases, when compared with control preparations (age, sex, and stain), sheaths and fibres of this tract were decreased and/or distorted. In the detailed presentation of Aring and Engel (1945b), changes in this fasciculus are also described. Interruptions or degeneration of the dorso-longitudinal fasciculus, which is believed to carry impulses from hypothalamic centres to autonomic nuclei of the brain-stem, combined with abnormalities of descending hypothalamic tracts which course through the lateral reticular substance, may explain much of the autonomic dysfunction which appears to originate from brain-stem nuclei.

The thalamus was extensively studied because of the cystic lesion described by Aring and Engel (1945b) which had destroyed portions of the dorsomedial nucleus, the internal medullary lamina, and the lateral nucleus of the right thalamus, and also because of the presence of the sensory component of the Riley-Day syndrome. One side of the reticular formation in their case was affected also. The cyst may have been a coincidental lesion, possibly of vascular origin. If autonomic dysfunction can result from such a cyst, then there is a possibility of secondary dysautonomia. Lesions in this position have been noted, however, many times, and clinical dysautonomia as a result is certainly rare. Their patient undoubtedly had clinical dysautonomia along with a unilateral lesion in the diencephalon. These investigators found no abnormalities of the hypothalamus. We failed also to reveal any changes in the nuclei of either anterior or posterior segments of the hypothalamus or other parts of the diencephalon.

In both of our cases, there are abnormalities which underlie the sensory disturbances in these patients. Case 1 , for instance, had loss of fibres of both the lateral and ventral spinothalamic tracts. There were no spinal cord sections in case 2 , hence we could not be sure of the findings in that portion of the neuraxis, but there were changes in the spino-thalamic tracts of the medulla and in all probability similar changes were present in the spinal cord. Loss of these tracts helps to explain the relative indifference to pain in these patients.

Absence of sheaths and/or sheath alterations in the mesencephalic tract of the fifth nerve may account for the lack of sensory response to stimu-D lation of the fifth nerve and, in addition, the opacityo and ulceration of the cornea.

The abnormal proprioceptive responses in the form of imbalance, ataxia, irregular hypotonia, and $\mathcal{C O N}^{\circ}$ in some cases, absent deep tendon reflexes, are largely due to abnormalities of both the ascending posterior columns and spino-cerebellar tracts, in the absence of cerebellar changes. It will be noted in the $\Rightarrow$ Table that Aring and Engel (1945b) also found loss of myelin sheaths in ascending columns of the gracilus and cuneatus, and Cohen and Solomon (1955) found, in addition, atrophy of the restiform $\frac{\bar{s}}{\frac{\rho}{\alpha}}$. body.

In a preliminary note, Linde and Westover (1962)ळ have suggested that the ganglion cells and myenteric ${ }_{-}$ plexuses of the gastrointestinal tract of children with ${ }^{\circ}$ familial dysautonomia are normal. In the present $\vec{\omega}$ study this was not strictly true, since abnormalities of $\omega$ the coeliac plexus, pelvic ganglia, and thoracic sympathetic ganglia were found. The black masses notedo in the distorted ganglion cell cytoplasm are con- $-\mathrm{N}$ sidered to be significant, although non-specific, i silver deposits. The vacuoles and focal cloudiness of $\vec{\omega}$ the discrete structures of the cytoplasm imply that ${ }_{-}^{-}$ some of the ganglia are actually undergoing dissolution. There was no phagocytic reaction preser. In case 2 , similar autonomic ganglia were ngto available for study, but nonetheless there weep vacuoles in some ganglia of the bowel wall.

It is certainly evident from the above description + that the anatomical substrate of this disorder is a widespread involvement of the nervous system, both central and peripheral, with unequivocal involvement $\overline{-}$ of the tracts of the reticular formation. Although the anatomical lesions may help to explain many clinical features of the disorder, ideas concerning $\stackrel{2}{\rightarrow}$ their pathogenesis are still conjectural.

The changes noted in peripheral autonomic ganglia certainly merit further histochemical study, and though Riley (1957) has reported effects of sympathectomy in these patients, no reports on pathological anatomy or microhistochemistry have? been made. That such studies may be highly signi- $\frac{5}{3}$ ficant is indicated by the work of Smith, Taylor, and Wortis (1963) who found evidence of abnormal cate-윽 cholamine metabolism in familial dysautonomia. In

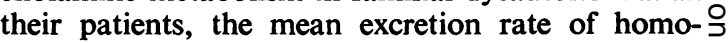
vanillic acid (derived from dopamine, a pressor amine $\rightarrow$ precursor) was shown to be twice that of controls. Loss of critical regulation of catechol secretion from $N$ autonomic ganglia by central abnormalities and/or excesses of acetylcholine, as suggested by Hutchison 0 and Hamilton (1962), could readily account for both $\omega$ massive catechol discharge as well as for periods of low catechol output. 
The argyrophilic masses noted in the peripheral autonomic ganglia of case 1 were first thought to represent abnormal ripening or poorly controlled storage of either catechol or catechol precursorcontaining granules. Preliminary histochemical tests done on this material, however, showed that both Schmorl's reaction and Gomori's silver niethenamine test were negative, indicating the unlikely phenolic nature of the cytoplasmic pigment. It is postulated, therefore, that the abnormal accumulation of argyrophilic material in a 3-year-old child represents excessive deposition of ganglion cell pigment.

\section{SUMMARY}

Pathological studies of familial dysautonomia in two Jewish siblings revealed a combination of medullary, pontine reticular formation, and dorso-longitudinal tract demyelination; degeneration, pigmentation, and loss of ganglion cells of the coeliac plexus, thoracic and pelvic sympathetic ganglia, all of which could account for clinical dysautonomia.

Alterations of spino-thalamic tracts, ascending posterior columns, posterior roots, spinocerebellar tracts, and mesencephalic tracts of the fifth nerve may serve to explain abnormal sensory responses and corneal changes in these patients.

All changes appeared slowly progressive with little or no phagocytic response. These changes are discussed in relation to previously reported studies, and attention is directed to the necessity for histochemical investigation of catechol amine storage and release in this condition.

Dr. A. Miller, presently pathologist St. Catherine's Hospital, Helena, Montana, did the necropsy on case 1.

\section{REFERENCES}

Aring, C. D., and Engel, G. L. (1945a). Arch. Neurol. Psychiat. (Chic.), 54, 37.

(1945b). Ibid. 54, 44

Cohen, P, and Solomon, N. H. (1955), J. Pediat, 46, 663.

Hutchison, J. H., and Hamilton, W. (1962). Lancet, 1, 1216.

Linde, L. M. (1956). Pediatrics, 18, 692.

- , and Westover, J. L., (1962). Ibid., 29, 303.

Magoun, H. W. (1939). Res. Publ. Ass. nerv. Ment. Dis., 20, 270.

Pearse, A. G. E. (1960). Histochemistry, 2nd ed., Churchill, London.

Riley, C. M., Day, R. L., Greeley, D. McL., and Langford, W. S. (1949). Pediatrics, 3, 468.

- (1957). Advanc. Pediat., 9, 157.

Smith, A. A., Taylor, T., and Wortis, S. B. (1963). New Engl. J. Med., 268, 705. 